\title{
PENGEMBANGAN BUKU AJAR BERBASIS LOKAL MATERI KEANEKARAGAMAN LABA-LABA DI KOTA METRO SEBAGAI SUMBER BELAJAR ALTERNATIF BIOLOGI UNTUK SISWA SMA KELAS $X$
}

\author{
Erna Suwarni \\ SMA Negeri 1 Metro \\ E-mail: ernasuwarni@yahoo.co.id
}

\begin{abstract}
The textbook is one of learning resources that can be developed by teachers in learning activities. Textbook lesson in the form of material substance systematically arranged to show the integrity of the competencies that will be controlled by learners in learning activities. Textbooks can assist teachers in delivering learning materials in order to achieve learning objectives. The purpose of this research is to develop locally-based textbook on materials spider diversity in Metro City as a source of alternative learning biology, knowing the quality of textbooks based on the qualifications of matter, pedagogy, and legibility, as well as to study the response of students to textbooks and cognitive outcomes. Product specification expected in this study is a locally-based textbook that can be used as a biology's alternative learning resource that can measure cognitive learning outcomes. This study uses research and development with $4 D$ development model developed by $S$. Thiagarajan et al, which consists of four stages of development that define, design, develop, and disseminate. Data obtained from tests of cognitive learning outcomes in the form of tabulated data to test the validity, reliability, and homogeneity with SPSS 16.0 so that it can be known whether there is a difference in average learning outcomes pre-test and post-test that uses a textbook and do not use textbooks by using t-test. The calculation data using t-test average yield obtained on the control class that does not use the textbook is 7.03 and the class textbook treatment using the results obtained an average of 8.10. Conclusion: textbook produced has been validated by the user and learning experts, and fit for use. And there is the difference in average learning outcomes of students between class control and class treatment.
\end{abstract}

Kata Kunci: Buku ajar, keanekaragaman, su mber belajar

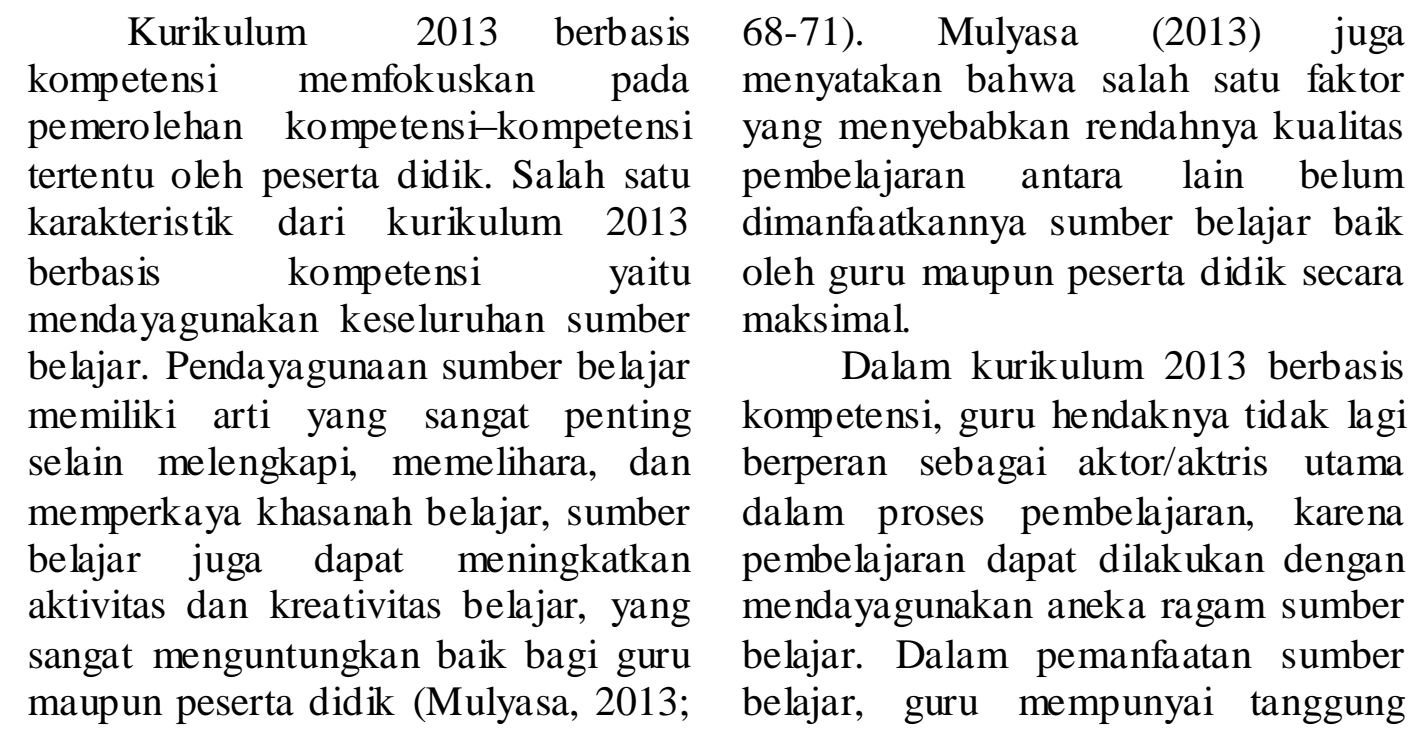


jawab membantu peserta didik belajar agar belajar lebih mudah, lebih lancar, dan lebih terarah. Oleh sebab itu, guru dituntut untuk memiliki kemampuan khusus yang berhubungan dengan pemanfaatan sumber belajar (Karwono, 2012: 140). Kegiatan pembelajaran dapat berjalan efektif dan efesien jika tersedia sumber belajar, dan salah satu contoh sumber belajar yaitu bahan ajar dalam bentuk buku ajar. Buku ajar merupakan salah satu buku yang menjadi acuan kegiatan belajar peserta didik.

Menurut Millah dkk (2012) dalam jurnalnya mengatakan bahwa buku ajar merupakan seperangkat materi substansi pelajaran yang disusun secara sistematis menampilkan keutuhan dari kompetensi yang akan dikuasai oleh peserta didik dalam kegiatan pembelajaran. Buku ajar dapat membantu guru dalam menyampaikan materi pembelajaran, sehingga tujuan pembelajaran dapat tercapai. Selain itu juga bahan ajar atau pun buku ajar yang ada, dan yang digunakan di sekolah belum memanfaatkan sumber belajar secara maksimal, seperti pemanfaatan potensi yang ada di lingkungan sekitar. Menurut beberapa guru biologi SMA/MA di Kota Metro, bahan ajar dalam bentuk buku ajar yang memanfaatkan lingkungan sekitar ataupun berbasis lokal di Kota Metro belum tersedia. Apalagi buku ajar biologi yang membahas tentang keanekaragaman laba-laba di Kota Metro. Biasanya guru memberikan contoh keanekaragaman makhluk hidup secara umum saja yang tertulis di buku referensi, tanpa mengkajinya lebih dalam lagi dengan mengamati keanekaragaman makhluk hidup yang ada di lingkungan sekitarnya seperti hewan laba-laba yang ada di Kota Metro.

\section{METODE}

Penelitian ini merupakan penelitian pengembangan, dengan model pengembangan 4-D yang dikembangkan S. Thiagarajan, Dorothy S. Semmel, dan Melvyn I Semmel (1974) terdiri dari empat tahap pengembangan yaitu define, design, develop, dan disseminate atau diadaptasikan menjadi model 4-P yaitu pendefinisian, perancangan, pengembangan, dan penyebaran (Trianto, 2009: 189).

Desain uji coba produk yang dilakukan pada penelitian ini meliputi uji materi (dosen), uji praktisi (guru), dan uji pengguna (peserta didik). Berdasarkan hasil uji produk tersebut dilakukan revisi terhadap model buku ajar yang dikembangkan. Instrumen yang digunakan dalam pengumpulan data pada proses pengembangan buku ajar adalah berupa hasil tes dan angket.

Penilaian kelayakan buku ajar dilakukan oleh praktisi atau pengguna dan ahli (expert) pembelajaran. Praktisi atau pengguna yang dipilih sebagai penilai tersebut yaitu seorang guru biologi SMA, seorang guru bahasa, dan seorang ahli pembelajaran yang berkompeten di bidang pembelajaran biologi. Adapun aspek yang dinilai dari model panduan meliputi: aspek isi buku ajar, bahasa, dan penyajian. Kualifikasi ahli pembelajaran dalam hal ini meliputi kualifikasi dalam dua aspek, yaitu ahli dalam aspek materi (biologi), keterbacaan, dan ahli dalam aspek pembelajaran (pedagogi). Komponen yang dinilai meliputi aspek isi (content), keterbacaan/penyajian, dan pedagogi. Hasil perhitungan berupa persentase kemudian dikelompokkan berdasarkan kriteria interpretasi skor menurut Riduwan (dalam Asih; 2014) seperti tersaji pada tabel 1 . 
Pengujian dilakukan melalui eksperimen, dengan menggunakan Pretest-Postest Control Group Design untuk mengetahui efektivitas penggunaan buku ajar. Untuk mengetahui ada tidaknya efek dari penggunaan buku ajar terhadap kelompok perlakuan, maka diperlukan kelompok non perlakuan (kontrol) sebagai pembanding. Kondisi sekolah yang dijadikan kontrol diupayakan sama dengan tempat validasi produk, yaitu berada pada sekolah yang sama. Bagi kelompok perlakuan maupun kontrol, untuk mengukur aspek pengetahuan, keduanya diberi pre-test dan post-test (pada tabel 2). Kemudian pengaruh treatment dianalisis dengan menggunakan statistik t-test melalui program SPSS 16.0.

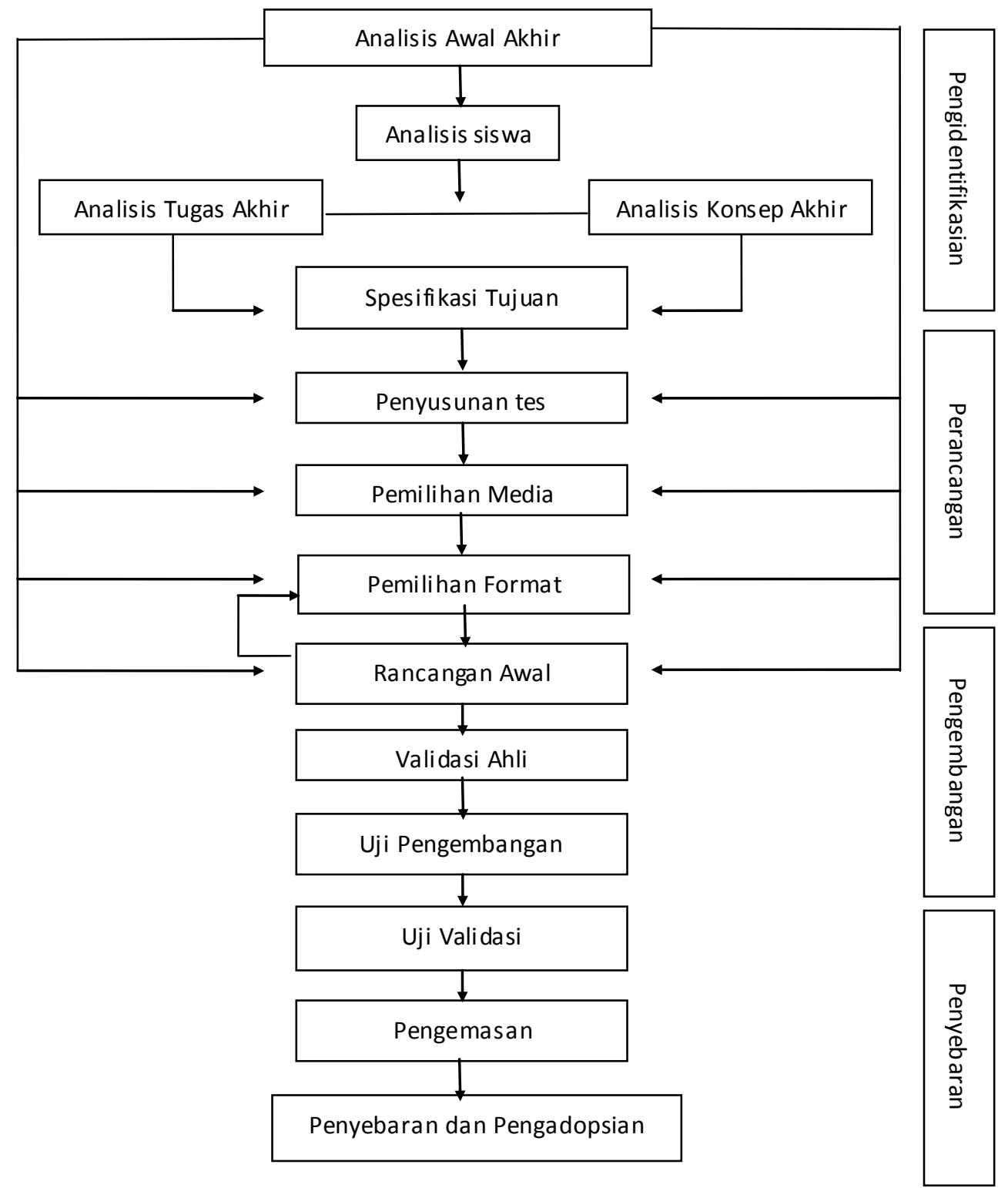

Gambar 1. Model Pengembangan Perangkat Pembelajaran 4D Thiagarajan (Sumber: Trianto, 2009) 
Tabel 1. Kategori Tingkat Kelayakan Bahan Ajar Menurut Ahli dan Pengguna

\begin{tabular}{l|l}
\hline Skor & Kategori \\
\hline $0 \%-20 \%$ & tidak baik \\
\hline $21 \%-40 \%$ & kurang baik \\
\hline $41 \%-60 \%$ & cukup baik \\
\hline $61 \%-80 \%$ & baik \\
\hline $81 \%-100 \%$ & sangat baik \\
\hline
\end{tabular}

Tabe12. Desain Validasi Produk, Diadaptasi dari Sugiyono (2012:112)

\begin{tabular}{c|c|c|c|c|c}
\hline \multicolumn{3}{|c|}{ Kelas Kontrol } & \multicolumn{3}{c}{ Kelas perlakuan (menggunakan buku ajar) } \\
\hline $\begin{array}{c}\text { Pre-tes } \\
(\mathrm{x})\end{array}$ & $\begin{array}{c}\text { Post-tes } \\
(\mathrm{y})\end{array}$ & $\begin{array}{c}\text { A } \\
(\mathrm{y}-\mathrm{x})\end{array}$ & $\begin{array}{c}\text { Pre-tes } \\
(\mathrm{x})\end{array}$ & $\begin{array}{c}\text { Post-tes } \\
(\mathrm{y})\end{array}$ & $\mathrm{B}$ \\
& & & & & \\
\hline
\end{tabular}

HASIL

Setelah melakukan tahapan pengidentifikasian, perancangan, dan pengembangan buku ajar yang sudah dirancang, dilakukan penilaian oleh validator yaitu 1 orang guru biologi, 1 orang ahli materi yang berkompeten dibidang pembelajaran biologi, serta 1 orang ahli bahasa. Aspek yang dinilai oleh validator meliputi struktur/format, materi/isi, serta bahasa.

Tabe13. Hasil Penilaian Pengguna dan Ahli Terhadap Buku Ajar yang Dikembangkan

\begin{tabular}{c|l|c}
\hline No. & \multicolumn{1}{|c}{ Penilai } & \multicolumn{1}{|c}{ Kateg ori } \\
\hline 1 & Gu ru Bio logi: Sugiyono, M.Pd. & Sangat Baik (97\%) \\
\hline 2 & Ahli Bahasa : Sri Wijayanti, S.Pd. & Sangat baik (82\%) \\
\hline 3 & Ahli Materi : Dr. Hening Widowati, M.Si. & Sangat baik (96\%) \\
\hline
\end{tabular}

Tabel 4. Hasil Validasi Keterbacaan Peserta Didik Terhadap Buku Ajar yang Dikembangkan

\begin{tabular}{|l|l|l|l|}
\hline No & \multicolumn{1}{|c|}{ Kriteria } & \multicolumn{1}{|c|}{ Rata-rata persentase (\%) } & \multicolumn{1}{c|}{ Kategori } \\
\hline 1 & Tampilan fisik buku ajar & $88 \%$ & Sangat baik \\
\hline 2 & Materi / isi & $88,5 \%$ & Sangat baik \\
\hline 3 & Bahasa & $86,5 \%$ & Sangat baik \\
\hline $\begin{array}{l}\text { Rata-rata keterbacaan peserta didik terhadap } \\
\text { buku ajar }\end{array}$ & $87,67 \%$ & Sangat baik \\
\hline
\end{tabular}

Berdasarkan analisis uji kesamaan dua rata-rata didapatkan nilai $\mathrm{t}$ hitung $>\mathrm{t}$ tabel $(2,049>1,701)$ pada taraf 5\% dimana nilai $\mathrm{dk}=\mathrm{n}-2=30-2$ $=28$ dengan nilai t table yaitu 1,701 (Furqon, 2011:282) maka Ho ditolak.
Kesimpulan ada perbedaan rata-rata hasil belajar menggunakan buku ajar dengan rata-rata hasil belajar biologi tanpa menggunakan buku ajar. Dimana pada kelas perlakuan yang menggunakan buku ajar sebagai 
sumber belajar alternatif peserta didik memiliki rata-rata nilai 8,10 lebih tinggi dibandingkan dengan nilai ratarata kelas kontrol yaitu 7,03.

\section{PEMBAHASAN}

Buku ajar merupakan media pembelajaran cetak yang dapat digunakan untuk memudahkan pendidik dan peserta didik guna meningkatkan kompetensinya. Siswa dipandang sebagai subjek belajar yang perlu dilibatkan secara aktif dalam proses pembelajaran, dan guru hanyalah seorang fasilitator yang membimbing dan mengkoordinasikan kegiatan belajar siswa. Bahan ajar berupa buku ajar ini dapat memudahkan proses pembelajaran dan memiliki daya tarik serta mampu memotivasi siswa untuk lebih aktif dalam proses pembelajaran, lebih interaktif, dan lebih kritis dalam menjawab masalah-masalah yang berhubungan dengan materi keanekaragaman hayati. (Ramansyah, 2013).

Berdasarkan hasil uji perbandingan penggunaan buku ajar, diketahui ada perbedaan rata-rata hasil belajar pada kelas kontrol dan kelas perlakuan. Hal tersebut dikarenakan pembelajaran pada kelas perlakuan menggunakan buku ajar menekankan bagaimana siswa belajar dengan memanfaatkan lingkungan sekitar sebagai sumber belajar. Selain itu materi yang yang disajikan bersifat sistematis dan menggunakan bahasa komunikatif, lugas, dan mudah dipahami oleh peserta didik. Dalam proses pembelajarannya, siswa dapat memperoleh pengalaman dan pengetahuan sendiri guna melatih kemampuan intelektualnya.

Berdasarkan hasil penelitian Syamsi (2013), Anggela (2013), pembelajaran menggunakan buku ajar dapat memudahkan proses pembelajaran sehingga membantu pencapaian ketuntasan kompetensi peserta didik. Hal ini disebabkan karena buku ajar mudah dipahami oleh peserta didik terlihat pada respon siswa pada tingkat keterbacaan terhadap buku ajar tergolong sangat baik.

\section{KESIMPULAN DAN SARAN Kesimpulan}

Sistematika penulisan penyajian materi pada buku ajar runtut di mulai dari bagian pendahuluan, halaman isi/batang tubuh, dan bagian penutup. Hal ini sesuai dengan syarat penyusunan buku ajar yang baik yang tercantum pada pedoman penyusunan buku ajar. Pada dasarnya penyusunan buku ajar terbagi menjadi tiga bagian yaitu bagian pembukaan, isi, dan bagian penutup (Depdiknas, 2006).

Materi

pembelajaran

keanekaragaman hayati yang dikembangkan juga mengandung aspek keaktifan, keterampilan, dan kemampuan berpikir peserta didik melalui pengamatan/observasi keanekaragaman laba-laba yang berbasis lokal. Hal ini ditandai dengan adanya pertanyaan atau kegiatan yang disajikan di dalam buku ajar pada setiap babnya dan isi materi pada buku ajar memiliki prinsip keajegan, sistematis, dan mengaitkannya dengan perkembangan ilmu terkini. Hal ini sesuai dengan saran Gultom (2012) yang menyatakan bahwa materi buku ajar hendaknya bersifat relevan, memuat bahan/pembahasan yang linear, dan merupakan satu kesatuan yang utuh (sistematis).

Bahasa yang digunakan dalam buku ajar ini sederhana, lugas, dan mudah dipahami serta bersifat komunikatif. Selain itu bahasa yang digunakan sesuai dengan EYD yang benar, serta menggunakan peristilahan 
yang sesuai dengan konsep pokok bahasan. Hal ini sesuai dengan kaidah penulisan buku ajar yaitu menggunakan bahasa Indonesia yang baku dan mudah dipahami. (Gultom, 2012).

\section{Saran}

Berdasarkan hasil pengembang an dalam penelitian ini, maka penulis menyarankan:

1. Peserta didik dapat menggunakan buku ajar keanekaragaman labalaba sebagaii sumber belajar alternatif dan sumber bacaan untuk menambah wawasan peserta didik.

2. Guru dapat menggunakan buku ajar keanekaragaman laba-laba sebagai salah satu bahan ajar dalam pembelajaran di kelas yang dapat dikembangkan melalui pembelajaran berbasis inkuiri.

3. Guru dapat membuat buku ajar keanekaragaman hayati pada hewan lain yang ada di Kota Metro, sehingga dapat meningkatkan kompetensi guru dan memperkaya wawasan peserta didik.

4. Sekolah agar mendukung dan melengkapi fasilitas pembelajaran yang mendukung proses pembelajaran bagi guru dan peserta didik agar dapat mengembangkan pengetahuan

\section{DAFTAR RUJUKAN}

Anggela, M. 2013. Pengembangan Buku Ajar Bermuatan Nilai-nilai Karakter Pada Materi Usaha dan Momentum untuk Pembelajaran Fisika Siswa Kelas XI SMA. Pillar of Physics Education. Vol. 1 63-70.

Asih, T. 2014. Pengembangan Model Panduan Pembelajaran Keterampilan Proses Sains Biologi SMA/MA. Tesis tidak diterbitkan. Metro. Program Pascasarjana Universitas Muhammadiyah Metro.

Depdiknas. 2006. Pedoman Penulisan Buku Pelajaran, Penjelasan Standar Mutu Buku Pelajaran Bahasa Indonesia. Jakarta; Pusat perbukuaan, Departement Pendidikan Nasional

Furqon. 2011. Statistika Terapan untuk Penelitian. Bandung. Penerbit Alphabeta.

Gultom, S. 2012. Pedoman Penulisan Buku Ajar Peningkatan Kompetensi Pendidik Pendidikan Nonformal. Jakarta. Kemendikbud.

Karwono. 2012. Belajar dan Pembelajaran. Jakarta: PT Raja Grafindo Persada.

Millah, E. dkk. 2012. Pengembangan Buku Ajar Materi Bioteknologi di Kelas XII SMA IPIEMS Surabaya Berorientasi Sains, Teknologi, Lingkungan, dan Masyarakat (SETS). E-journal Bio Edu. Volume 1.

Mulyasa, 2013. Pengembangan dan Implementasi Kurikulum 2013. Bandung: PT Remaja Rosdakarya.

Ramansyah, W. 2013. Pengembangan Bahan Ajar Mata Kuliah Strategi Pembelajaran untuk Mahasiswa Pendidikan Guru Sekolah Dasar. Madura Bangkalan. Jurnal Wid yagogik, Volume1 Nomer 1.

Sugiyono. 2012. Metode Penelitian

Pendidikan Pendekatan Kuantitatif, Kualitatif, dan $R \& D$. Bandung: Alfabetha.

Syamsi, K. 2013. Pengembangan Model Buku Ajar Membaca Berdasarkan Pendekatan Proses 
Bagi Siswa SMP. Yogyakarta.

Jurnal Cakrawala Pendidikan Th.XXXII No 1.

Trianto. 2009. Mendesain Model

Pembelajaran Inovatif-Progresif.

Jakarta: Kencana Prenada Media

Group. 